\title{
The broth in my brother's brothel: Morpho-orthographic segmentation in visual word recognition
}

\author{
KATHLEEN RASTLE \\ Royal Holloway, University of London, Surrey, England \\ MATTHEW H. DAVIS \\ MRC Cognition and Brain Sciences Unit, Cambridge, England \\ and \\ BORIS NEW \\ Royal Holloway, University of London, Surrey, England
}

\begin{abstract}
Much research suggests that words comprising more than one morpheme are represented in a "decomposed" manner in the visual word recognition system. In the research presented here, we investigate what information is used to segment a word into its morphemic constituents and, in particular, whether semantic information plays a role in that segmentation. Participants made visual lexical decisions to stem targets preceded by masked primes sharing (1) a semantically transparent morphological relationship with the target (e.g., cleaner-CLEAN), (2) an apparent morphological relationship but no semantic relationship with the target (e.g., corner-CORN), and (3) a nonmorphological form relationship with the target (e.g., brothel-BRОтн). Results showed significant and equivalent masked priming effects in cases in which primes and targets appeared to be morphologically related, and priming in these conditions could be distinguished from nonmorphological form priming. We argue that these findings suggest a level of representation at which apparently complex words are decomposed on the basis of their morpho-orthographic properties. Implications of these findings for computational models of reading are discussed.
\end{abstract}

Morphologically complex words introduce a significant challenge to modern theories of visual word recognition. For over 25 years (since Taft \& Forster, 1975), empirical evidence gathered from across the world's languages has pointed to a visual word recognition system in which letter strings are analyzed in terms of their constituent morphemes. In numerous studies it has been demonstrated, for example, that the frequency of a stem (e.g., dark) affects the time taken to recognize a complex word derived from that stem (e.g., darkness; Bertram, Schreuder, \& Baayen, 2000; Niswander, Pollatsek, \& Rayner, 2000). In other studies, it has been demonstrated that the recognition of a stem target (e.g., CLEAN) is speeded by the prior presentation of a morphologically related prime (e.g., cleaner; Stanners, Neiser, Hernon, \& Hall, 1979) and that this facilitation cannot be explained by summed effects of semantic and orthographic priming

We acknowledge the support of Economic and Social Research Council Grant RES-000-22-0464, awarded to the first author. We are grateful to Marc Brysbaert, Neil Mulligan, Jay Rueckl, and two anonymous reviewers for comments on an earlier version of this manuscript. Correspondence concerning this article may be addressed to K. Rastle, Department of Psychology, Royal Holloway, University of London, Egham, Surrey TW20 0EX, England (e-mail: kathy.rastle@rhul.ac.uk).
(Rastle, Davis, Marslen-Wilson, \& Tyler, 2000). These and other data suggest that the visual recognition of complex words involves some process of decomposition, or segmentation, that allows access to a core stem representation. The aim of the research presented here is to investigate what information is used to segment a complex word into its morphemic constituents during visual word recognition - and, in particular, whether semantic information plays a role in that segmentation.

In the dominant view of morphology (see, e.g., MarslenWilson, Tyler, Waksler, \& Older, 1994), morphemes provide an important element of structure to the otherwise arbitrary mapping between word forms and their meanings. In general, words that are spelled similarly do not mean similar things (e.g., mink is unrelated in meaning to pink, monk, milk, and mint). However, morphemes form "islands of regularity" in this mapping because (1) the meanings of stems are largely preserved in their derivations (e.g., the meaning of dark is preserved in darkness and darken) and (2) affixes alter the meanings of stems in highly predictable ways (e.g., the words darker, smarter, and faster are related in meaning to the words dark, smart, and fast, respectively, in the same way). Morphemes are the building blocks of meaning and, indeed, provide the primary means for lexical productivity (i.e., the creation of new words-e.g., unfaxable). 
This conceptualization of morphology has been embraced in many recent theories of morphological processing (Giraudo \& Grainger, 2000; Marslen-Wilson et al., 1994; Plaut \& Gonnerman, 2000; Rueckl \& Raveh, 1999), which propose that complex words share lexical representations with their morphemic constituents only in cases in which there is a semantically transparent relationship between the complex word and its stem. Semantically transparent complex words are those comprised of morphemic elements such that the meaning of the complex form can be derived from the meanings of its constituents (e.g., the meaning of hunter can be derived from the meanings of hunt + er). Complex words are semantically opaque if their meanings are unrelated to the meanings of their constituents (e.g., the meaning of witness cannot be derived from the meanings of wit + ness). These theories are supported by observations from priming tasks that tap central semantic levels of the language system, including cross-modal priming and visual priming with fully visible primes: Derived words prime their stems only if there is a semantic relationship between them (Longtin, Segui, \& Hallé, 2003; MarslenWilson et al., 1994; Rastle et al., 2000).

Recent research using masked priming of visual word recognition (a priming technique in which primes are presented so briefly that they are unavailable for report; Forster \& Davis, 1984) appears potentially inconsistent with this characterization, however. Several studies have demonstrated statistically equivalent facilitation (relative to priming from totally unrelated words) from semantically transparent and semantically opaque masked primes on the recognition of stems (Rastle \& Davis, 2003; Rastle et al., 2000) and derived words (Feldman \& Soltano, 1999) — a null result possibly implicating a meaningindependent morphological decomposition procedure operating in early visual word recognition. However, when these priming effects are measured against nonmorphological form priming effects - a comparison that is necessary if one is to conclude that the effects are specifically morphological - the data appear instead to favor meaning-dependent decomposition. Priming from semantically transparent complex English words is statistically greater than nonmorphological form priming (Feldman, 2000; Pastizzo \& Feldman, 2002; Rastle et al., 2000), whereas priming from semantically opaque complex English words is not (Rastle et al., 2000). The behavior of semantically opaque complex English words is therefore ambiguous: Priming effects from these words cannot be distinguished statistically from either semantically transparent priming effects or form priming effects. Only by resolving this ambiguity can we determine whether morphological decomposition in early visual word recognition is meaning dependent or meaning independent.

A crucially important issue in solving this problem concerns the characterization of opaque morphological and nonmorphological form conditions. Opaque pairs have previously been defined (see, e.g., Marslen-Wilson et al.,
1994; Rastle et al., 2000) as ones that have a morphological relationship established on etymological/historical grounds, but no semantic relationship (e.g., witness-WIT). Form control conditions (Marslen-Wilson et al., 1994; Rastle et al., 2000) have previously comprised etymologically and semantically unrelated pairs (e.g., brothelBROTH), some of which appear to have a morphological relationship (e.g., corner-CORN; -er surfaces as an affix in other English words). This characterization may have contributed to the ambiguous results described earlier. If a meaning-independent morphological segmentation procedure operates in early visual word recognition, we believe that the segmentation would be governed not by etymological characterizations but by the appearance of morphological complexity: Any stimulus bearing a morphological surface structure (i.e., an existing stem and affix, such as corner) would be decomposed, irrespective of its semantic transparency or etymological characterization. In accordance with this theory, Longtin et al. (2003) observed that the recognition of French stems was speeded significantly and equivalently by transparent, etymologically related opaque, and etymologically unrelated opaque masked primes, and that this facilitation could not be attributed to simple form overlap. Unfortunately, stimulus matching in Longtin et al. left small but significant differences across conditions in terms of target frequency, prime-target form overlap, and length that could not be fully accounted for in the analysis of data. Additional research is needed to establish clearly whether there is a morphemic segmentation procedure in early visual word recognition that operates independently of semantic information.

In this work, we investigate morphological decomposition in early visual word recognition by measuring masked priming effects under three conditions: (1) when primes and targets share a semantically transparent morphological relationship (e.g., cleaner-CLEAN), (2) when primes and targets share an apparent morphological relationship but no semantic relationship (e.g., corner-CORN), and (3) when targets are embedded within primes in a nonmorphological manner (e.g., brothel-BROTH). If the representations accessed in masked priming are structured on the basis of semantically defined morphological units, then we should observe masked priming effects in conditions in which the relationship between primes and targets is semantically transparent (e.g., cleaner-CLEAN), and these effects should be significantly greater than those for conditions in which there is no semantic relationship between primes and targets (e.g., corner-CORN and brothel-BROTH). If, however, representations are decomposed on the basis of orthographically defined morphological units, then we should observe priming effects whenever primes and targets appear to be morphologically related (e.g., cleaner-CLEAN and corner-CORN), and these effects should be significantly greater than those observed when primes and targets share a nonmorphological form relationship (e.g., brothel-вROTH). 


\section{METHOD}

\section{Participants}

The participants were 62 undergraduate volunteers from Royal Holloway, University of London. All of the participants had normal or corrected-to-normal vision and were native speakers of British English. The participants were offered $£ 5$ or course credit in exchange for their time.

\section{Stimuli and Apparatus}

One hundred fifty prime-target pairs were selected from the CELEX English database (Baayen, Piepenbrock, \& van Rijn, 1993), 50 in each of three conditions. Pairs in the transparent condition bore a semantically transparent morphological relationship (e.g., cleaner-CLEAN). Pairs in the opaque condition had no semantic relationship but bore an apparent morphological relationship (e.g., corner-CORN). Although some of the prime-target pairs in this condition had an etymological relationship (e.g., department-DEPART), this was not a requirement. Transparent and opaque primes were constructed in such a way that they could be parsed perfectly into the target and an English suffix. Suffixes appearing in opaque and transparent primes were chosen so that their usage as English suffixes was approximately equivalent: Suffixes in the opaque condition are used in $M=357$ words, and those in the transparent condition are used in $M=401$ words $[t(98)<1]$. Pairs in the form condition bore an orthographic relationship but no semantic or apparent morphological relationship (e.g., brothel-BROTH). Primes in this condition comprised the target plus a nonmorphological ending - an ending not used as a suffix in English, or occurring only very infrequently as a suffix (i.e., in no more than four orthographically transparent word forms). Although most endings used in form primes never surface as suffixes (e.g., -el), others were admitted that are used very infrequently in this manner (e.g., $-d$, which occurs as a suffix in the single word doggoned, and $-n$, which occurs in silvern and orthographically opaque born). Occasionally, letters that correspond to more common English suffixes appeared in form primes (e.g., -age in fuselage), but these could never be segmented perfectly from their stems (e.g., removing age from fuselage leaves fusel, not the target FUSE). Test items are contained in the Appendix.

Primes and targets across conditions were matched as closely as possible on target frequency, prime frequency, target neighborhood size, target length, target family size (i.e., the number of its derivations), and form overlap (expressed as number of prime letters divided by number of target letters). The mean values of these variables across the three conditions, along with one-way analysis of variance (ANOVA) statistical test data, are shown in Table 1. Despite this extensive matching, we wished to ensure that differential priming across conditions could not have been due to small differences within each of these variables or to interactions between them. We therefore treated each of these factors as covariates in the items analysis of our priming data.

Unrelated control primes were selected for each of the 150 target words. Control primes were orthographically, morphologically, and semantically unrelated to targets and were matched as closely as possible to each related prime on frequency $[t(149)=1.41]$ and length $[t(149)=-.57]$. All control primes were morphologically complex (suffixed) words.

In order to corroborate our intuitions about semantic transparency, we extracted semantic relatedness values for each prime-target pair in the experimental conditions using the Latent Semantic Analysis (LSA; Landauer \& Dumais, 1997) Web facility (http://lsa.colorado.edu). Semantic relatedness values from LSA (calculated through the automated analysis of large amounts of written text) have previously been shown to correlate highly with subjective ratings of semantic relatedness (Rastle et al., 2000). Results revealed no difference in LSA similarity values for form primes and targets $(.08)$ and opaque primes and targets $[.07 ; t(95)<1]$. LSA similarity values for transparent primes and targets (.38) were, however, significantly greater than those for opaque primes and targets $[t(92)=-8.20]$ and for form primes and targets $[t(93)=-7.71]$.

Fifty pairs of unrelated words were added to the item set to reduce the prime-target relatedness proportion to .37 . These filler targets were matched on length to the three sets of word targets $[F(3,196)<1]$ and were preceded by unrelated suffixed word primes. An additional 200 nonword targets, matched to word targets on length $[t(348)<1]$, were preceded by unrelated suffixed word primes.

Targets from each condition were divided at random into two equal lists for counterbalancing purposes, with half of the items in each list preceded by related primes. The participants received only one experimental list and, therefore, participated in all priming conditions but saw each target word only once.

Stimulus presentation and data recording were controlled by DMDX software (Forster \& Forster, 2003) running on a Pentium III personal computer. A two-button response box was used to record lexical decisions, with the "yes" response button controlled by the dominant hand.

\section{Procedure}

The participants were tested individually in a dimly lit, quiet room. They were advised that they would be seeing a series of letter strings presented one at a time and that they would be required to decide as quickly and accurately as possible whether or not each string was a word. The participants were not told of the existence of the prime stimulus. Each prime was presented in lowercase for $42 \mathrm{msec}$; each was preceded by a $500-\mathrm{msec}$ forward mask (\#\#\#\#\#\#) and followed immediately by a target in uppercase that remained on the screen until a response was made. Targets were presented in a different random order for each participant, and the participants were given 10 practice trials before the experiment began.

\section{RESULTS}

Reaction times (RTs) for correct responses were collected and cleaned to remove outliers. Thirteen data points over $1,800 \mathrm{msec}$ were removed $(0.15 \%$ of the data). Furthermore, three prime-target pairs from the

Table 1

Mean Values of Stimulus Characteristics for Items Across the Three Conditions

\begin{tabular}{lccrc}
\hline & \multicolumn{3}{c}{ Condition } & \\
\cline { 2 - 4 } \multicolumn{1}{c}{ Property } & Transparent & Opaque & Form & ANOVA \\
\hline Frequency (T) & 52.32 & 40.14 & 49.04 & $F(2,149)=0.26$, n.s. \\
Frequency (P) & 24.92 & 51.92 & 30.50 & $F(2,149)=1.05$, n.s. \\
Neighborhood size (T) & 2.16 & 2.20 & 2.58 & $F(2,149)=1.22$, n.s. \\
Length, in letters (T) & 4.92 & 4.80 & 4.64 & $F(2,149)=2.16$, n.s. \\
Family size (T) & 3.38 & 3.40 & 2.34 & $F(2,149)=1.74$, n.s. \\
Overlap & .69 & .69 & .67 & $F(2,149)=0.61$, n.s. \\
\hline
\end{tabular}


form condition (against-AGAIN, textile-TEXT, and tactileТАСТ) were incorrectly classified as "nonmorphological" and were removed. Remaining latency and error data by subjects are shown in Table 2. Item data are contained in the Appendix.

Data were analyzed by two-factor ANOVA, with the magnitude of priming (i.e., control - primed RT or error rate) treated as the dependent variable. Condition (three levels) was treated as a repeated factor in the subjects analysis and as an unrepeated factor in the items analysis; list (two levels) was treated as an unrepeated factor in both analyses. Into the items analysis, we also entered several covariates (as was explained in the Stimuli and Apparatus section): target frequency, test prime frequency, target neighborhood size, target length, form overlap, and target family size. ${ }^{1}$ Effects were considered statistically significant if they reached the $p<.05$ level.

Latency analyses revealed a significant effect of condition on priming $\left[F_{1}(2,120)=5.60, M S_{\mathrm{e}}=1,488\right.$; $\left.F_{2}(2,135)=3.49, M S_{\mathrm{e}}=2,370\right]$. Further investigation of this effect revealed no statistical difference between priming in the transparent and opaque conditions $\left[F_{1}(1,60)<1\right.$, $\left.F_{2}(1,90)<1\right]$. However, priming in both transparent and opaque conditions was significantly greater than priming in the form condition [transparent vs. form, $F_{1}(1,60)=$ $13.52, F_{2}(1,87)=6.40$; opaque vs. form, $F_{1}(1,60)=$ $\left.5.06, F_{2}(1,87)=3.90\right]$. Error analyses did not reveal a similar effect of condition on priming $\left[F_{1}(2,120)<1\right.$, $\left.F_{2}(2,135)<1\right]$ and are not considered further.

Because this was a between-target comparison, it is important to establish that the pattern of priming effects on latency data cannot be explained by baseline differences across items. We therefore selected a subset of items (form, 29; opaque, 34; transparent, 28) that yielded statistically equivalent baseline (control) RTs $(614,615$, and $616 \mathrm{msec}$, respectively; $F<1)$ and error rates [7.56\%, $6.43 \%$, and $4.75 \%$, respectively; $F(2,90)=1.1]$ and performed the items analysis of latency data described above. ${ }^{2}$ The pattern of effects was unchanged. A main effect of condition on priming $\left[F(2,79)=4.15, M S_{\mathrm{e}}=1,332.62\right]$ reflected significantly greater priming in both the transparent and opaque conditions than in the form condition [transparent vs. form, $F(1,47)=7.93$; opaque vs. form, $F(1,53)=4.34]$, but no difference in priming between the transparent and opaque conditions $(F<1)$.

Table 2

Mean Latencies (in Milliseconds), Error Data (\%Error), and Priming Effects

\begin{tabular}{|c|c|c|c|c|c|c|}
\hline \multirow[b]{3}{*}{ Relatedness } & \multicolumn{6}{|c|}{ Condition } \\
\hline & \multicolumn{2}{|c|}{ Transparent } & \multicolumn{2}{|c|}{ Opaque } & \multicolumn{2}{|c|}{ Form } \\
\hline & $M$ & $\%$ Error & $M$ & $\%$ Error & $M$ & $\%$ Error \\
\hline Related primed & 570 & 2.7 & 598 & 8.6 & 635 & 14.1 \\
\hline Control primed & 597 & 4.5 & 620 & 10.6 & 639 & 17.1 \\
\hline Priming effect & 27 & 1.8 & 22 & 2.0 & 4 & 3.0 \\
\hline
\end{tabular}

\section{DISCUSSION}

In this work, we investigated the nature of morphological decomposition at early stages of visual word recognition. The participants made visual lexical decisions to stem targets when these targets were preceded by masked primes sharing (1) a semantically transparent morphological relationship with the target (e.g., cleanerCLEAN), (2) an apparent morphological relationship but no semantic relationship with the target (e.g., corner-CORN), and (3) a nonmorphological form relationship with the target (e.g., brothel-BROTH). The results were unambiguous. Conditions in which prime and target had the appearance of a morphological relationship produced significant (and equivalent) priming effects, and priming in both of these conditions could be distinguished statistically from nonmorphological form priming. These findings corroborate the French data of Longtin et al. (2003) while ruling out the potential contribution of confounding variables, and confirm a pattern that has, as yet, only been suggested in English masked priming (see, e.g., Feldman \& Soltano, 1999; Pastizzo \& Feldman, 2002; Rastle \& Davis, 2003; Rastle et al., 2000). This body of literature introduces a functional departure from the standard view of morphology, according to which the decomposition of polymorphemic words is governed by semantic transparency (Marslen-Wilson et al., 1994). These results point instead to a rapid process of morphological segmentation that operates on any printed word that contains a stem and an affix, irrespective of semantic transparency (or indeed of an etymological relationship between the complex word and its stem; see also Longtin et al., 2003).

The notion of obligatory morphological decomposition, blind to semantic and etymological factors, sits within the localist theoretical traditions of affix stripping (Taft \& Forster, 1975) and, more recently, interactive activation (Taft, 1994). Contemporary computational models of visual word recognition within the latter tradition (see, e.g., Coltheart, Rastle, Perry, Langdon, \& Ziegler, 2001) might consider these findings in terms of a morphological level of representation that resides between letter units and the orthographic lexicon and that is activated through explicit morphemic segmentation of letter strings. Letter strings comprising a morphological surface structure (e.g., cleaner, corner) would activate sublexical morphemic units (e.g., $\{$ clean $\},\{c o r n\},\{e r\})$, which would, in turn, activate units in the orthographic lexicon (i.e., where lexical decisions are made). Priming effects for such words could be simulated as residual activation in sublexical morphemic units produced by masked, morphologically structured primes. It is important to understand that although our findings are inconsistent with localist theories in which decomposition is semantically based (see, e.g., Giraudo \& Grainger, 2000; MarslenWilson et al., 1994), they do not rule out the possibility that such decomposition occurs at other, higher levels of 
the language system. Rather, our findings demonstrate that there is a purely structural decomposition, which arises in early visual word recognition, that is not captured by these theories alone.

Our findings are similarly inconsistent with distributedconnectionist simulations of the form-meaning mapping (see, e.g., Davis, van Casteren, \& Marslen-Wilson, 2003; Plaut \& Gonnerman, 2000; Rueckl \& Raveh, 1999), where learned (hidden-unit) representations of derived words and their stems overlap to the degree that there is a semantically transparent relationship between them. Although these simulations can, under some circumstances, produce significant priming effects for items with an opaque relationship (Plaut \& Gonnerman, 2000), the size of this priming effect never approaches that for items with a transparent relationship. Our findings point instead to a purely structural morphemic segmentation, which we believe characterizes learned representations at an earlier stage of the model: in orthography itself. Interestingly, this type of structural segmentation is assumed in all published simulations of the form-meaning mapping: The network is provided with an orthographic input that has been presegmented into stems and affixes. How that segmentation is achieved has not, however, been considered.

One possible morpho-orthographic segmentation mechanism is provided by bigram and trigram frequency contours across words (Seidenberg, 1987). Where stems and affixes typically have very high bigram and trigram frequencies, these frequencies are much lower across morpheme boundaries. This trough pattern is seen clearly in
Figure 1, which displays bigram and trigram frequencies for 12,282 morphologically complex words taken from the CELEX lemma database (Baayen et al., 1993). In this analysis, we consider only the $65 \%$ of complex words in which morphemic units are combined without orthographic changes to either the stem or the affix (e.g., excitement, but not excitable).

On the basis of the statistical structure that is apparent in the orthographic form of complex words, a connectionist network that learns the orthographic properties of morphologically complex words may divide complex words into their constituent morphemes without being trained on an explicit, morphologically segmented input and without information concerning the semantic properties of stem and affix combinations. We refer the reader to the analogous problem of developing lexical representations from exposure to connected speech (in which word boundaries are not explicitly marked), in which similar accounts based on analyses of biphone and triphone probabilities within and across word boundaries (see, e.g., Brent, 1999; Cairns, Shillcock, Chater, \& Levy, 1997) are proposed.

In summary, we have observed that the stem of an English bimorphemic word is accessed rapidly in visual word recognition irrespective of whether the meaning of the carrier word is related to the stem. These findings implicate a type of morphological decomposition that is functionally distinct from the semantically based decomposition that has dominated recent localist (Giraudo \& Grainger, 2000; Marslen-Wilson et al., 1994) and distributed-connectionist (Plaut \& Gonnerman, 2000;

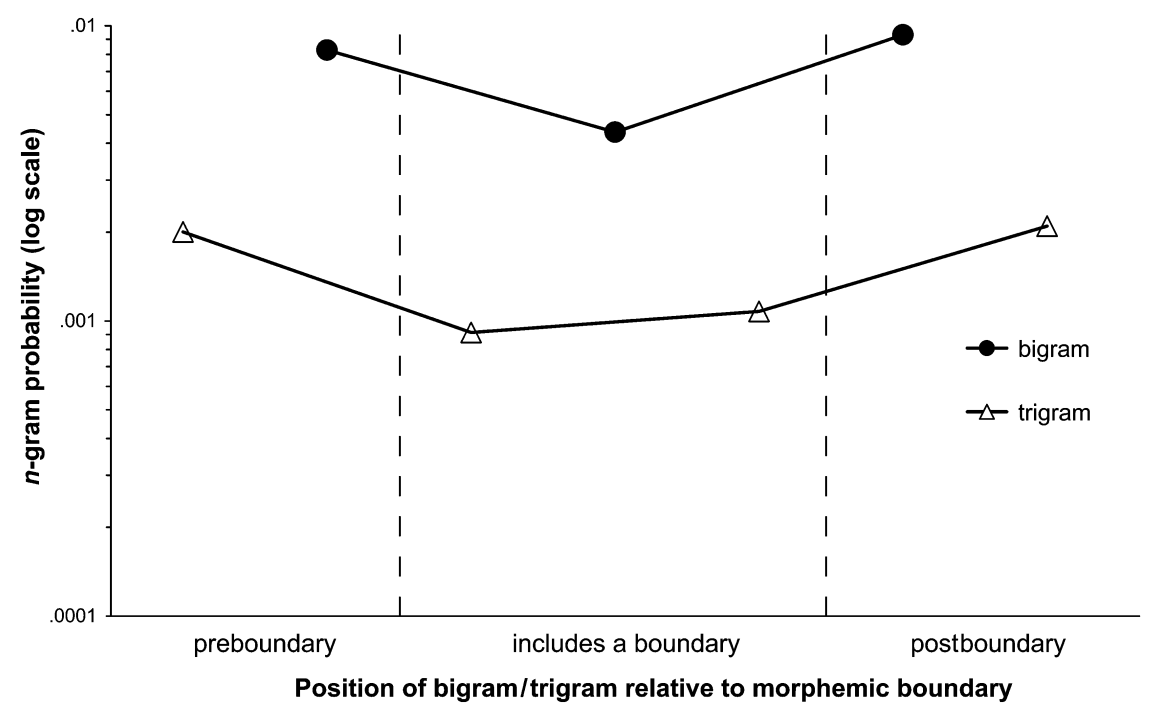

Figure 1. Average bigram and trigram frequencies relative to the location of a morphological boundary in 12,282 morphologically complex words from the CELEX database (Baayen et al., 1993). Data points for the trigram curve for the word excitement would be ite (preboundary), tem and eme (including a boundary), and men (postboundary). Data points for the bigram curve for the word excitement would be te (preboundary), em (including a boundary), and me (postboundary). 
Rueckl \& Raveh, 1999) accounts. Rather, these findings implicate a level of representation, accessed in early visual word recognition, at which morphological decomposition is defined on a purely orthographic basis, where words are segmented simply because they have a morphological structure (e.g., corner). This proposition raises important challenges for future modeling efforts within both localist and distributed-connectionist approaches to visual word recognition.

\section{REFERENCES}

BaAyen, R. H., Piepenbrock, R., \& van Rijn, H. (1993). The CELEX lexical database [CD-ROM]. Philadelphia: University of Pennsylvania, Linguistic Data Consortium.

Bertram, R., Schreuder, R., \& BaAyen, R. H. (2000). The balance of storage and computation in morphological processing: The role of word formation type, affixal homonymy, and productivity. Journal of Experimental Psychology: Learning, Memory, \& Cognition, 26, 489511.

Brent, M. R. (1999). Speech segmentation and word discovery: A computational perspective. Trends in Cognitive Sciences, $\mathbf{3}, 294-$ 301 .

Cairns, P., Shillcock, R., Chater, N., \& Levy, J. (1997). Bootstrapping word boundaries: A bottom-up corpus-based approach to speech segmentation. Cognitive Psychology, 33, 111-153.

Coltheart, M., Rastle, K., Perry, C., Langdon, R., \& Ziegler, J. (2001). DRC: A dual route cascaded model of visual word recognition and reading aloud. Psychological Review, 108, 204-256.

Davis, M. H., van Casteren, M., \& MARSLEN-Wilson, W. D. (2003). Frequency effects in processing inflected Dutch nouns: A distributed connectionist account. In R. H. Baayen \& R. Schreuder (Eds.), Morphological structure in language processing (pp. 427-462). Berlin: Mouton de Gruyter.

Feldman, L. B. (2000). Are morphological effects distinguishable from the effects of shared meaning and shared form? Journal of Experimental Psychology: Learning, Memory, \& Cognition, 26, 1431-1444.

Feldman, L. B., \& Soltano, E. G. (1999). Morphological priming: The role of prime duration, semantic transparency, and affix position. Brain \& Language, 68, 33-39.

FoRSTER, K. I., \& DAVIS, C. (1984). Repetition priming and frequency attenuation in lexical access. Journal of Experimental Psychology: Learning, Memory, \& Cognition, 10, 680-698.

Forster, K. I., \& Forster, J. C. (2003). DMDX: A Windows display program with millisecond accuracy. Behavior Research Methods, Instruments, \& Computers, 35, 116-124.

GIRAUDO, H., \& GRAINGER, J. (2000). Effects of prime word frequency and cumulative root frequency in masked morphological priming. Language \& Cognitive Processes, 15, 421-444.
Landauer, T. K., \& Dumais, S. T. (1997). A solution to Plato's problem: The latent semantic analysis theory of acquisition, induction, and representation of knowledge. Psychological Review, 104, 211-240.

Longtin, C.-M., Segui, J., \& Hallé, P. A. (2003). Morphological priming without morphological relationship. Language \& Cognitive Processes, 18, 313-334.

MARslen-Wilson, W. D., Tyler, L. K., Waksler, R., \& Older, L. (1994). Morphology and meaning in the English mental lexicon. Psychological Review, 101, 3-33.

NisWander, E., Pollatsek, A., \& Rayner, K. (2000). The processing of derived and inflected suffixed words during reading. Language \& Cognitive Processes, 15, 389-420.

PastizZo, M. J., \& FeldMAN, L. B. (2002). Discrepancies between orthographic and unrelated baselines in masked priming undermine a decompositional account of morphological facilitation. Journal of Experimental Psychology: Learning, Memory, \& Cognition, 28, 244249.

Plaut, D. C., \& Gonnerman, L. M. (2000). Are non-semantic morphological effects incompatible with a distributed connectionist approach to language processing? Language \& Cognitive Processes, 15, 445-485.

RASTLE, K., \& DAVIS, M. [H.] (2003). Reading morphologically complex words: Some thoughts from masked priming. In S. Kinoshita \& S. J. Lupker (Eds.), Masked priming: State of the art (pp. 279-305). New York: Psychology Press.

Rastle, K., Davis, M. H., Marslen-Wilson, W. D., \& Tyler, L. K. (2000). Morphological and semantic effects in visual word recognition: A time course study. Language \& Cognitive Processes, 15, $507-$ 538.

RuecKL, J. G., \& Raveh, M. (1999). The influence of morphological regularities on the dynamics of a connectionist network. Brain \& Language, 68, 110-117.

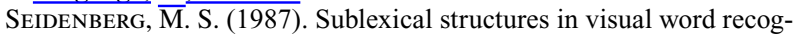
nition: Access units or orthographic redundancy? In M. Coltheart (Ed.), Attention and performance 12: The psychology of reading (pp. 245-263). Hillsdale, NJ: Erlbaum.

Stanners, R. F., Neiser, J. J., Hernon, W. P., \& Hall, R. (1979). Memory representation for morphologically related words. Journal of Verbal Learning \& Verbal Behavior, 18, 399-412.

TAFT, M. (1994). Interactive activation as a framework for understanding morphological processing. Language \& Cognitive Processes, $\mathbf{9}_{2}$ 271-294.

TAFT, M., \& Forster, K. I. (1975). Lexical storage and retrieval for prefixed words. Journal of Verbal Learning \& Verbal Behavior, 14, 638647.

\section{NOTES}

1. Analyses of latency data were repeated without these covariates. There were no changes to the statistical pattern of priming effects. 2. We are grateful to Neil Mulligan for suggesting this analysis. 
APPENDIX

Stimuli and Item Data

\begin{tabular}{|c|c|c|}
\hline Target & Prime (RT, in msec) & Control (RT, in msec) \\
\hline \multicolumn{3}{|c|}{ Form Condition } \\
\hline AGAIN & against $(-)$ & perhaps $(-)$ \\
\hline ARSE & arsenal (622) & timidly (643) \\
\hline BROTH & brothel (739) & warfare (706) \\
\hline CANDID & candidacy (663) & epileptic (710) \\
\hline COMMA & command (764) & equally (824) \\
\hline DIAL & dialog $(564)$ & lately (573) \\
\hline ETHER & ethereal (768) & rumbling (718) \\
\hline FORCE & forceps (558) & prudish (602) \\
\hline FUSE & fuselage (645) & citation (669) \\
\hline GLAD & glade (603) & cuffs $(641)$ \\
\hline INFER & inferno $(630)$ & frilled (822) \\
\hline JERK & jerkin (614) & twisty (692) \\
\hline PHONE & phonetic (546) & dreadful (585) \\
\hline PLUS & plush (587) & filmy (684) \\
\hline QUART & quartz $(650)$ & roller (663) \\
\hline SALMON & salmonella (560) & petulantly (630) \\
\hline SHOVE & shovel (621) & tricky $(700)$ \\
\hline SIGH & sight (627) & happy (635) \\
\hline SQUAW & squawk (731) & oddity (781) \\
\hline STIR & stirrup (612) & buoyant (607) \\
\hline STUD & studio (677) & gently (651) \\
\hline SURF & surface $(578)$ & medical (612) \\
\hline TACT & tactile $(-)$ & spindly $(-)$ \\
\hline TWIN & twinkle (571) & cheaply (577) \\
\hline VILLA & villain $(650)$ & grossly (666) \\
\hline APPEND & appendix (579) & believer ( 758$)$ \\
\hline BASIL & basilica (637) & princely (595) \\
\hline BUTT & button (728) & prayer (648) \\
\hline COLON & colonel $(724)$ & ability (735) \\
\hline DEMON & demonstrate (585) & instruction (555) \\
\hline ELECT & electron (623) & suburban (620) \\
\hline EXTRA & extract (568) & justify (559) \\
\hline FREE & freeze $(638)$ & golden (546) \\
\hline GALA & galaxy (784) & keeper (727) \\
\hline HEAVE & heaven (782) & firmly (663) \\
\hline INTERN & international (667) & revolutionary (651) \\
\hline PARENT & parenthesis (576) & lectureship (533) \\
\hline PLAIN & plaintiff (553) & absurdity (548) \\
\hline PULP & pulpit (584) & gifted (594) \\
\hline RABBI & rabbit (927) & weekly (761) \\
\hline SCRAP & scrape (570) & ninety (589) \\
\hline SHUN & shunt (769) & itchy (696) \\
\hline SMUG & smuggle (612) & twelfth (638) \\
\hline STAMP & stampede (547) & defector (572) \\
\hline STUB & stubborn (615) & moisture (607) \\
\hline STUN & stunt (634) & misty $(675)$ \\
\hline SURGE & surgeon (689) & novelty (642) \\
\hline TEXT & textile $(-)$ & booklet (-) \\
\hline TWIT & twitch (617) & lesser (643) \\
\hline WEIR & weird (813) & manly (703) \\
\hline \multicolumn{3}{|c|}{ Opaque Condition } \\
\hline AMEN & amenable (655) & palpably (655) \\
\hline $\mathrm{ARCH}$ & $\operatorname{archer}(550)$ & feudal (582) \\
\hline BOARD & boarder (531) & factual (552) \\
\hline BRISK & brisket (622) & foundry (637) \\
\hline COAST & coaster $(555)$ & muffler (614) \\
\hline COURT & courteous $(561)$ & developer (586) \\
\hline CROOK & crooked (584) & pottery (664) \\
\hline DEPART & department (592) & production (580) \\
\hline
\end{tabular}


APPENDIX (Continued)

\begin{tabular}{|c|c|c|}
\hline Target & Prime (RT, in msec) & Control (RT, in msec) \\
\hline EARL & early (637) & within $(605)$ \\
\hline FLEET & fleeting (583) & simplify (655) \\
\hline FRUIT & fruitless (551) & alcoholic (590) \\
\hline GLUT & gluten (663) & bridal (759) \\
\hline HEART & hearty $(550)$ & folder (551) \\
\hline INFANT & infantry (599) & validity (608) \\
\hline IRON & irony $(570)$ & sandy (538) \\
\hline NUMB & number $(610)$ & really (659) \\
\hline PLAN & planet (527) & editor (603) \\
\hline PLUM & plumage (543) & broiler (551) \\
\hline QUEST & question (620) & actually (592) \\
\hline SCULL & scullery (732) & narrowly (757) \\
\hline SIGN & signet (535) & frosty (549) \\
\hline SPLINT & splinter $(588)$ & idealism (694) \\
\hline THICK & thicket (547) & scruffy (552) \\
\hline TROLL & trolley $(665)$ & naughty (653) \\
\hline UNIT & united (619) & others (577) \\
\hline AMP & ample (686) & widen (692) \\
\hline AUDIT & audition (675) & selfless (668) \\
\hline BRAND & brandy (594) & safely (569) \\
\hline BUZZ & buzzard (573) & loyally (574) \\
\hline COUNT & country (580) & service $(571)$ \\
\hline CRAFT & crafty $(541)$ & vainly (579) \\
\hline CRYPT & cryptic (633) & dweller (602) \\
\hline DISC & discern (578) & starter (598) \\
\hline FACET & facetious (752) & distantly (767) \\
\hline FLICK & flicker (558) & adviser (613) \\
\hline GLOSS & glossary (558) & sufferer (590) \\
\hline GRUEL & grueling (707) & existent (709) \\
\hline HELM & helmet (689) & brutal (773) \\
\hline INVENT & inventory (579) & murderous (660) \\
\hline LIQUID & liquidate (557) & extremism (571) \\
\hline ORGAN & organic (569) & leaflet $(563)$ \\
\hline PLUCK & plucky (583) & winger (651) \\
\hline PUTT & putty $(755)$ & fishy (731) \\
\hline RATION & rational (616) & steadily (640) \\
\hline SECRET & secretary (616) & obviously (561) \\
\hline SNIP & sniper $(655)$ & hourly (679) \\
\hline STILT & stilted (621) & gaseous (759) \\
\hline TREAT & treaty $(539)$ & angler (575) \\
\hline TRUMP & trumpet (627) & chatter (718) \\
\hline WHISK & whisker (582) & coyness $(581)$ \\
\hline \multicolumn{3}{|c|}{ Transparent Condition } \\
\hline ACID & acidic $(527)$ & yearly (555) \\
\hline ADOPT & adopted (574) & kingdom (602) \\
\hline ANGEL & angelic (546) & watcher (554) \\
\hline BARON & baronet (661) & voucher (643) \\
\hline BLOOD & bloody (520) & active (533) \\
\hline FLESH & fleshy (550) & lovers (581) \\
\hline CREAM & creamy (522) & watery $(564)$ \\
\hline CLOUD & cloudless (551) & enactment (608) \\
\hline DRUNK & drunkard (529) & feathery (572) \\
\hline EMPLOY & employer (564) & addition (606) \\
\hline FILTH & filthy (693) & harden $(640)$ \\
\hline FLOAT & floater (555) & missive (571) \\
\hline GUILT & guilty (558) & formal (603) \\
\hline GOVERN & government (597) & situation (628) \\
\hline VIEW & viewer (526) & ranger (588) \\
\hline LEGEND & legendary (523) & anxiously (589) \\
\hline NORTH & northern (546) & friendly (628) \\
\hline OXYGEN & oxygenate (554) & fossilise (614) \\
\hline
\end{tabular}


APPENDIX (Continued)

\begin{tabular}{|c|c|c|}
\hline Target & Prime (RT, in msec) & Control (RT, in msec) \\
\hline QUIET & quieten $(504)$ & mimicry $(560)$ \\
\hline RISK & risky $(502)$ & downs (567) \\
\hline TUFT & tufted (663) & silken (798) \\
\hline DREAM & dreamer (493) & masonry (501) \\
\hline TEACH & teacher (538) & finally (559) \\
\hline TRAIN & trainee $(512)$ & cookery (541) \\
\hline BULB & bulbous (566) & leftist (657) \\
\hline ACRE & acreage (604) & plunder (595) \\
\hline ALARM & alarming (528) & composer $(507)$ \\
\hline RENEW & renewable (651) & exemption (688) \\
\hline BEARD & bearded (577) & thinker (569) \\
\hline вомВ & bomber (539) & lessen $(535)$ \\
\hline SCALD & scalding (608) & jauntily (749) \\
\hline CRITIC & critical (586) & tendency (604) \\
\hline MOURN & mourner (607) & tripper $(643)$ \\
\hline REACT & reaction (574) & physical (622) \\
\hline ERUPT & eruption (632) & vicarage (676) \\
\hline FIZZ & fizzle $(618)$ & touchy $(660)$ \\
\hline ARTIST & artistry (571) & calmness (548) \\
\hline GLOOM & gloomy (576) & miller (611) \\
\hline CHILL & chilly (576) & finely (691) \\
\hline INHIBIT & inhibitory (732) & amateurish (715) \\
\hline MARSH & marshy (651) & thorny $(567)$ \\
\hline NYMPH & nymphet (713) & acutely (795) \\
\hline POET & poetry (543) & dealer $(578)$ \\
\hline AGREE & agreement (527) & equipment (551) \\
\hline DIET & dietary (536) & wearily (565) \\
\hline SOFT & soften (538) & heroic $(569)$ \\
\hline GOLF & golfer (521) & thinly (543) \\
\hline TOAST & toaster (498) & wishful (503) \\
\hline GREEN & greenery (543) & snobbish (527) \\
\hline WIDOW & widowed (615) & beastly (583) \\
\hline
\end{tabular}

Note-RT, reaction time.

(Manuscript received April 30, 2003;

revision accepted for publication December 18, 2003.) 